\title{
Fabrication of Catalyst Layers on Inorganic-Organic Composite Membranes by Electrophoretic Deposition
}

\author{
Hirokazu MunAKATA, a, b Yuko NowATARI, a, b Tomohiko IshIDA, a, b \\ and Kiyoshi KANAMURA, ${ }^{\text {a }}$ *
}

\begin{abstract}
a Department of Applied Chemistry, Graduate School of Urban Environmental Science, Tokyo Metropolitan University (1-1 Minami-Ohsawa, Hachioji, Tokyo 192-0397, Japan)

b CREST, Japan Science and Technology Agency (4-1-8 Honcho, Kawaguchi, Saitama 332-0012, Japan)
\end{abstract}

Received May 22, 2006 ; Accepted August 9, 2006

\begin{abstract}
A membrane electrode assembly (MEA) was successfully prepared by electrophoretic deposition (EPD) process onto the inorganic-organic composite membrane composed of three-dimensionally ordered macroporous (3DOM) silica and 2-acrylamido-2-methylpropane sulfonic acid (AMPS) gel polymer. An ethanol suspension of carbon powders with Pt catalyst and ionomer was utilized to the EPD process. The catalyst layers fabricated by the EPD process were well-attached to both sides of the 3DOM composite membrane and those thicknesses were easily controlled by the EPD duration. The obtained MEA exhibited higher cell performance than an ordinary one prepared by decal transfer process, due to improvement in the contact between the 3DOM composite membrane and catalyst layers.
\end{abstract}

Key Words : Fuel Cell, Composite Membrane, Membrane Electrode Assembly, Electrophoretic Deposition

\section{Introduction}

Polymer electrolyte fuel cells (PEFCs) are promising candidates for portable and stationary power sources because they have high energy conversion efficiency and power density with no or low emissions. Especially, their applications for electric vehicles have attracted considerable attention and many efforts have been made on improving cell performance. A membrane electrode assembly (MEA) consisting of an electrolyte membrane and catalyst layers is the heart of a PEFC. DuPont's Nafion ${ }^{\circledR}$, a perfluorosulfonic acid polymer, is most widely studied as a solid electrolyte in PEFCs, due to its high proton conductivity and chemical stability. Despite having favorable properties, Nafion ${ }^{\circledR}$ has some critical drawbacks such as high cost, unstable thermal stability, poor selectivity of fuel permeation, and complicated production processes. This promotes researches to develop alternative materials and many kinds of sulfonated polymers have been proposed. ${ }^{1)}$ However, most of the polymer electrolytes easily expand or shrink depending on temperature and humidity. The dimensional changes of the membrane result in exfoliation of catalyst layers and fuel permeation through the membrane, namely decreases of reliability and lifetime of PEFCs. Addition of inorganic fillers into polymers is one of effective methods to improve mechanical strength of the polymers. ${ }^{2,3)}$ Another concept is a pore-filling composite membrane. ${ }^{4-6)}$ This kind of composite membrane is prepared from a porous substrate and a filling material that fills the pores of the substrate. The dimensional changes of the filling electrolyte are mechanically suppressed by the hard substrate matrix.

MEA fabrication is also a key point to develop PEFC performances. Not only the structure of catalyst layers where the electrochemical reactions occur to generate electrical power, but also the quality of the contact between the electrolyte membrane and catalyst layers strongly influence the catalyst and fuel utilization. Therefore, considerable efforts have been addressed to prepare favorable MEA structures. A decal transfer process, i.e. hot pressing of catalyst ink onto the membranes, has been widely used as a MEA fabrication method. ${ }^{7)}$ The contact between the membrane and catalyst layers was formed by melting of the membrane above the glass transition temperature. However, this method may not be suitable for very rigid membranes, especially for the composite membranes containing inorganic components. Electrophoretic deposition (EPD), another transfer process, is effective to fabricate coatings on hard substrates such as ceramics. ${ }^{8)}$ Charged particles in a suspension are electrophoresed and deposited onto the target substrate under an applied electric field. This method has many advantages, ex. easy control of the coating thickness and high uniformity of the coating structure, compared with the other coating processes. In our previous paper, we reported the preparation of uniformly porous catalyst layers onto a Nafion ${ }^{\circledR} 117$ membrane by the EPD process. ${ }^{9)}$ The prepared catalyst layer was well-attached to the Nafion ${ }^{\circledR}$ membrane and the resulting MEA exhibited high current density with about twice utilization of Pt catalyst compared with the MEA prepared by a decal transfer process. We describe here the application of EPD process to improve the contact problem between catalyst layers and a hard composite membrane consisting of three-dimensionally ordered macroporous (3DOM) silica and 2-acrylamido-2methyl-1-propane sulfonic acid (AMPS) polymer, and discuss the effect of the suspension composition and elec- 
trophoretic conditions on the cell performance.

\section{Experimental}

3DOM silica matrix used as a porous substrate for the pore-filling composite membrane was prepared by colloidal templating method using $500 \mathrm{~nm}$ polystyrene beads and $70 \sim 100 \mathrm{~nm}$ silica particles.5) The thickness of 3DOM silica matrix was $150 \mu \mathrm{m}$. An aqueous solution containing AMPS (Wako), $N, N^{\prime}$-methylenebisacrylamide (Wako), and ammonium persulfate (Wako) with concentrations of 4.82, $2.60 \times 10^{-1}$, and $4.38 \times 10^{-2} \mathrm{~mol} \mathrm{~kg}^{-1}$, respectively, was injected into the pores of the $3 \mathrm{DOM}$ silica matrix, and then heated at $60^{\circ} \mathrm{C}$ for $1 \mathrm{~h}$ to perform polymerization. The proton conductivity of the composite membrane was $3.1 \times 10^{-2} \mathrm{~S} \mathrm{~cm}^{-1}$ at $60^{\circ} \mathrm{C}$ under $90 \%$ relative humidity. The composite membrane was set at the middle of the EPD cell equipped with two platinum electrodes (Fig. 1). The left compartment contained $0.1 \mathrm{~mol}$ $\mathrm{dm}^{-3} \mathrm{HClO}_{4}$ aqueous solution, and the right had a catalyst suspension containing $40 \mathrm{wt} \%$ Vulcan XC72 fine carbonsupported $\mathrm{Pt}$ catalyst (Pt/C, $7 \mathrm{mg}$, Tanaka Kikinzoku Kogyo K. K.), an ion exchange ionomer, and ethanol (20 $\mathrm{ml}$, Wako). In this study, Nafion ${ }^{\circledR}(50 \mu \mathrm{l}, 5 \mathrm{wt} \%$ solution, Sigma-Aldrich Inc.) or AMPS polymer (20 $\mu$ l, $15 \mathrm{wt} \%$ solution, average $\mathrm{Mw}=2000000$, Sigma-Aldrich Inc.) was used as the ionomer that formed composite particles with $\mathrm{Pt} / \mathrm{C}$ in the suspension. The concentration of the ionomer was decided according to the optimized one in our previous paper. ${ }^{9}$ The size distribution of the composite particles in the suspension was investigated at room temperature by dynamic light scattering (DLS) using LB-550 (HORIBA, Ltd.). The composite particles were charged negatively due to sulfonic acid groups of the ionomer, so that those were moved to the positive electrode in the course of EPD. The EPD cell was immersed into ice bath to keep a temperature, and a constant DC voltage of $1000 \mathrm{~V}$ was applied between the two electrodes to obtain an average electric field of 125 $\mathrm{V} \mathrm{cm}{ }^{-1}$. After the EPD of a catalyst layer on one side of the composite membrane, both solutions for the cathode and anode compartments were removed, and then the membrane was dried at atmosphere. The same EPD process was applied on the opposite side of the membrane to fabricate the MEA. For comparison, hot press method was also conducted to fabricate MEAs. However, the catalyst layer was not successfully transferred onto the 3DOM composite membrane by an ordinary proce-

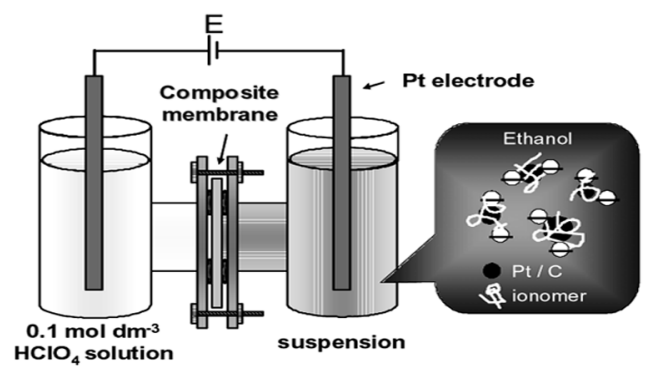

Fig. 1 Schematic illustration of the EPD cell used in this study. dure using Teflon blanks. Therefore, the MEA was prepared by simple contact of the composite membrane with the catalyst layer hot-pressed on a carbon paper. An ink consisting of $\mathrm{Pt} / \mathrm{C}(0.15 \mathrm{~g}), 5 \mathrm{wt} \% \mathrm{Nafion}{ }^{\circledR}$ solution $(1.0 \mathrm{~g})$, glycerin $(1.0 \mathrm{~g}$, Wako), and water $(0.75 \mathrm{~g})$ was prepared and painted on a carbon paper. After drying of the painted ink at $130{ }^{\circ} \mathrm{C}$ for $2 \mathrm{~h}$, the hot press process was performed to fabricate the catalyst layer on the carbon paper. The structure and morphology of the catalyst layer were observed with a scanning electron microscope (SEM, JEOL JSM-5310). The performance of the MEA was characterized as a single cell at $60{ }^{\circ} \mathrm{C}$ in $80 \%$ humidified hydrogen $\left(50 \mathrm{~cm}^{3} \mathrm{~min}^{-1}\right) /$ oxygen $\left(50 \mathrm{~cm}^{3}\right.$ $\left.\min ^{-1}\right)$ configuration.

\section{Results and Discussion}

Figure 2 shows the DLS results for the catalyst suspensions containing Nafion ${ }^{\circledR}$ or AMPS polymer as the ionomer. In both cases, the particle sizes were increased compared to that in the suspension containing only carbon particles. This result indicated that aggregates consisting of $\mathrm{Pt} / \mathrm{C}$ and the ionomer were formed. The average particle sizes in the Nafion ${ }^{\circledR}$ and AMPS suspension were $168 \mathrm{~nm}$ and $137 \mathrm{~nm}$, respectively. The formation of the composite particles is driven by hydrophobic interaction between $\mathrm{Pt} / \mathrm{C}$ and ionomers. The ionomer also worked as a surfactant in the prepared suspension. Accordingly, the composite particle was charged negatively by sulfonic acid groups of the ionomer and was moved to the positive electrode in the course of EPD. However, the AMPS polymer is more hydrophilic than Nafion ${ }^{\circledR}$, so that the aggregate formation in the AMPS suspension may be difficult. Therefore, smaller composite particles were obtained in the AMPS suspension, compared with Nafion ${ }^{\circledR}$.

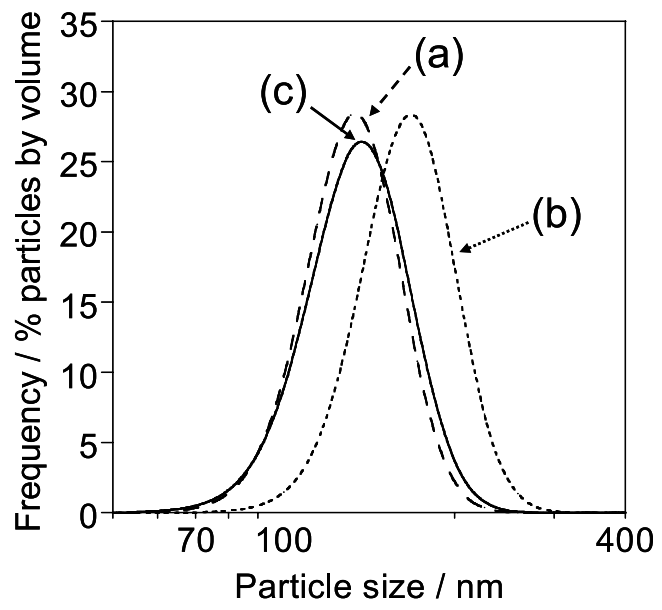

Fig. 2 Particle size distributions of (a) Pt/C $7 \mathrm{mg}$ in $20 \mathrm{ml}$ ethanol $\left(d_{\text {ave }}=133 \mathrm{~nm}, \sigma=11 \mathrm{~nm}\right.$ ); (b) Pt/C $7 \mathrm{mg}+5 \mathrm{wt} \%$ Nafion ${ }^{\circledR}$ solution $50 \mu$ in $20 \mathrm{ml}$ ethanol $\left(d_{\text {ave }}=168 \mathrm{~nm}, \sigma=13\right.$ nm); (c) Pt/C $7 \mathrm{mg}+15 \mathrm{wt} \%$ AMPS polymer solution $20 \mu \mathrm{l}$ in $20 \mathrm{ml}$ ethanol $\left(d_{\text {ave }}=137 \mathrm{~nm}, \sigma=12 \mathrm{~nm}\right)$. $d_{\text {ave }}$ and $\sigma$ are the average and standard deviation of the particle diameter, respectively. 
Figure 3 shows the photograph and the cross-sectional SEM images of the MEAs prepared by the EPD process. The catalyst layers prepared from the Nafion ${ }^{\circledR}$ suspension were well-attached to both sides of the 3DOM composite membrane and those surfaces were very smooth. Also in the case of the AMPS suspension, a similar MEA was obtained. Regardless of the kind of ionomer, uniform structure was formed on the 3DOM composite membrane. The thickness of the catalyst layer was increased linearly with the EPD duration as shown in Fig. 4. Even for a short EPD duration, a uniformity of the catalyst layer was kept. Thus, the thickness of the catalyst layer is easily controlled. This is one of the advantages of the EPD process. The deposition rate of the catalyst layer from the AMPS suspension was estimated as $90 \mathrm{~nm} \mathrm{~min}$. This value was smaller than that from the Nafion ${ }^{\circledR}$ suspension $\left(700 \mathrm{~nm} \mathrm{~min}{ }^{-1}\right)$. The mobility of the particles in the suspension is strongly affected by electrophoretic parameters such as applied electric field, the concentration and the charge of the particles. Actually, the distribution of the composite particles in the AMPS suspension was different from that in the Nafion ${ }^{\circledR}$ suspension, which would be one of reasons for the different deposition rate.

The performance of the MEA was examined by a single hydrogen-oxygen fuel cell. 80\% humidified hydrogen and dry oxygen was fed to the anode and cathode, respectively. The flow rates of gases were $50 \mathrm{~cm}^{3} \mathrm{~min}^{-1}$. Carbon cloth was used as gas diffusion layer and current collector. The measurement was conducted at $60{ }^{\circ} \mathrm{C}$.
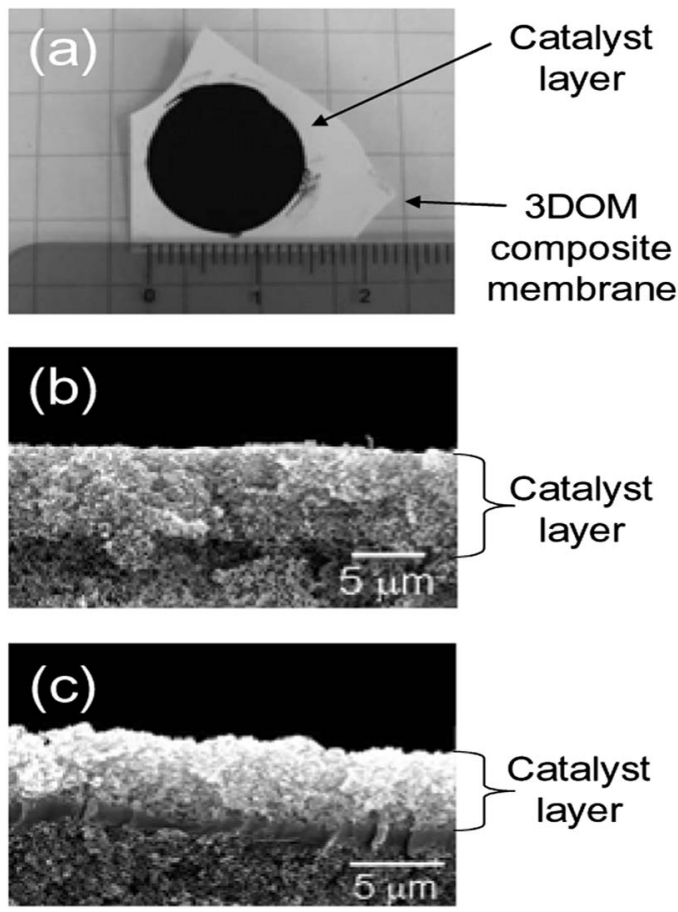

Fig. 3 Typical photograph and cross-sectional SEM images of the MEAs prepared by EPD process from (a) Nafion ${ }^{\circledR}$ suspension; (b) Nafion ${ }^{\circledR}$ suspension; (c) AMPS suspension, under electric field intensity of $125 \mathrm{~V} \mathrm{~cm}^{-1}$. The durations for (b) and (c) were $10 \mathrm{~min}$ and $30 \mathrm{~min}$, respectively.
Figure 5 shows the current-voltage curves for the MEAs prepared by the hot press method and the EPD process. The Pt loadings were $3 \mathrm{mg} \mathrm{cm}^{-2}$ (hot press), $0.16 \mathrm{mg} \mathrm{cm}^{-2}$ (EPD-Nafion ${ }^{\circledR}$ ), and $0.1 \mathrm{mg} \mathrm{cm}^{-2}$ (EPD-AMPS), respectively. The cell performance was increased by the application of the EPD process. This result may be obtained by a higher uniformity of the catalyst layer and improvement of the contact problem between the 3DOM composite membrane and the catalyst layer. In particular, the MEA prepared from the AMPS suspension exhibited good cell performance in spite of the low Pt loading. At the interface between an electrolyte membrane and a catalyst layer, protons must be transferred as smoothly as possible to obtain high current density. It is well known that protons transfer among ionic clusters consisting polar groups such as a sulfonic acid group in the electrolyte polymer. The number of these ionic clusters increases with an increase of water content and the number of sulfonic acid groups. ${ }^{10)}$ However, the size and

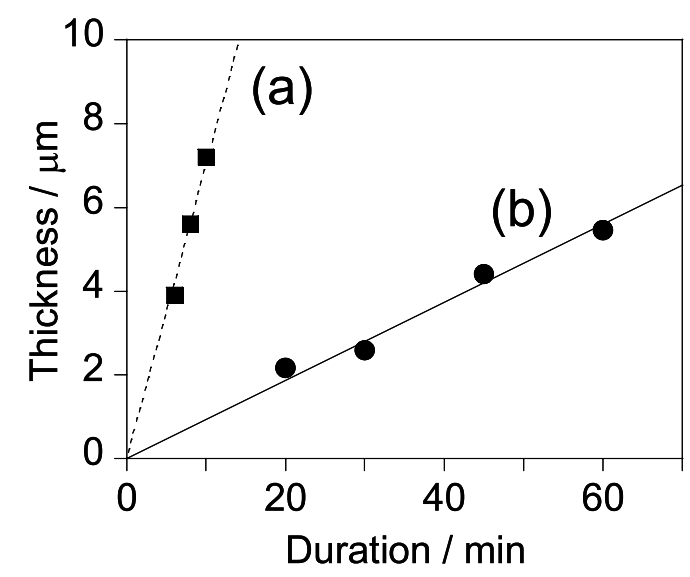

Fig. 4 Effect of the EPD duration on the thickness of the catalyst layer prepared from (a) Nafion ${ }^{\circledR}$ suspension; (b) AMPS suspension, under electric field intensity of $125 \mathrm{~V}$ $\mathrm{cm}^{-1}$.

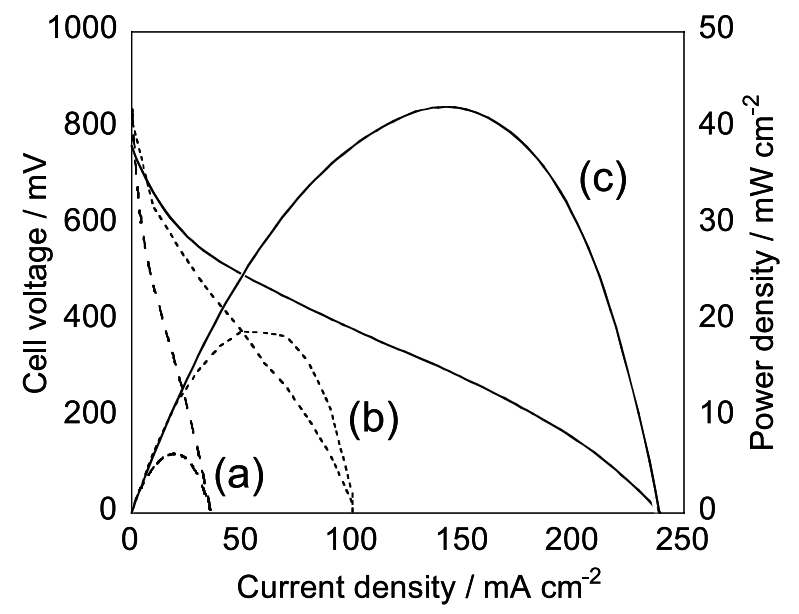

Fig. 5 Current-voltage curves for the MEAs prepared by (a) hot press method; (b) EPD process from Nafion ${ }^{\circledR}$ suspension; (c) EPD process from AMPS suspension. 
distribution of them were specific to the kind of electrolyte polymer. Although the catalyst layer prepared from the Nafion ${ }^{\circledR}$ suspension was well-attached to the 3DOM composite membrane, it was suspected microscopically that favorable contact for the proton transfer was formed because the chemical and physical properties of the Nafion ${ }^{\circledR}$ such as hydrophilicity and water uptake were different from those of the AMPS polymer used as the filling electrolyte in the 3DOM composite membrane. The structure of the catalyst layer, concerning catalyst activity, gas permeability, electrical conductivity, and so on, is also expected to be influenced by the kind of ionomer. A detailed study about structural factors is underway and will be reported in a further paper.

\section{Conclusion}

The EPD process has been performed to fabricate the MEA using the 3DOM silica composite membrane. The catalyst layers with uniform structures were successfully fabricated on both sides of the composite membrane. The contact problem between the hard composite membrane and the catalyst layer, which occurred in the MEA preparation by hot press method, was improved by using the EPD process. The MEA prepared from the catalyst suspension containing the AMPS polymer exhibited higher cell performance than that from Nafion ${ }^{\circledR}$ sus- pension. This result indicated that favorable selection of the ionomer for the electrolyte membrane was one of important factors to achieve the best cell performance.

\section{References}

1) M. A. Hickner, H. Ghassemi, Y. S. Kim, B. R. Einsla, and J. E. McGrath, Chem. Rev., 104, 4587 (2004).

2) Q. Li, R. He, J. O. Jensen, and N. J. Bjerrum, Chem. Mater., 15, 4896 (2003).

3) J. D. Kim, T. Mori, and I. Honma, J. Electrochem. Soc., 153, A508 (2006).

4) T. Yamaguchi, F. Miyata, and S. Nakao, J. Membr. Sci., 214, 283 (2003).

5) K. Kanamura, T. Mitsui, and H. Munakata, Chem. Mater., 17, 4845 (2005).

6) H. Munakata, D. Yamamoto, and K. Kanamura, Chem. Commun, 2005, 3986.

7) S. Q. Song, Z. X. Liang, W. J. Zhou, G. Q. Sun, Q. Xin V. Stergiopoulos, and P. Tsiakaras, J. Power Sources, 145, 495 (2005).

8) Y. Fukada, N. Nagarajan, W. Mekky, Y. Bao, H. S. Kim, and P. S. Nicholson, J. Mater. Sci., 39, 787 (2004).

9) H. Morikawa, N. Tsuihiji, T. Mitsui, and K. Kanamura, J. Electrochem. Soc., 151, A1733 (2004).

10) K. A. Mauritz and R. B. Moore, Chem. Rev., 104, 4535 (2004). 